\title{
Hepatitis C as a Risk Factor for Diabetes Type 2: Lack of Evidence in a Hospital in Central-West Brazil
}

Luce Marina Freires Corrêa da Costa ${ }^{1}$, Aparecida Duarte Hg Mussi ${ }^{2}$, Marylina Rodrigues Brianeze ${ }^{2}$ and Francisco José Dutra Souto ${ }^{3}$ ${ }^{1}$ Nurse School, Federal University of Mato Grosso; ${ }^{2}$ Central laboratory, Health Secretary of Mato Grosso State; ${ }^{3}$ Science Medical School, Federal University of Mato Grosso; Cuiabá, MT, Brazil

In order to assess the importance of $\mathrm{HCV}$ infection as a possible risk factor for type 2 diabetes mellitus, a casecontrol study was conducted, comparing the prevalence of $\mathrm{HCV}$ infection among diabetic and non-diabetic patients. Diabetic outpatients attending to a University Hospital in Central-West Brazil were evaluated between April and October 2005. A control group composed by patients from the same institution was matched by gender and age. Candidates to control group were included only if fasting glucose measures were under $100 \mathrm{mg} / \mathrm{dL}$. Diabetics and controls had blood samples taken in order to test for antibodies against HCV (anti-HCV) by enzyme-immunoassay. Polymerase chain reaction and immunoblot were performed to confirm the anti-HCV status. Each group included 206 participants. Despite of the groups were in general comparable. The diabetics had a greater body mass average and smaller family income. The prevalence of confirmed anti-HCV in the diabetic group was of $1.4 \%$, which was similar to the controls (1\%). Finding statistical difference may have been hampered by the low frequency of $\mathrm{HCV}$ infection in both groups. It was not possible to demonstrate a role of $\mathrm{HCV}$ as an etiologic factor in type 2 diabetes, since HCV infected patients represented a small portion of the overall diabetes cases. This finding does not allow to recommend regular screening for $\mathrm{HCV}$ infection in type 2 diabetics in this region.

Key-Words: Type 2 diabetes mellitus, case control study, risk factors, hepatitis C virus, epidemiology.

The association between hepatic cirrhosis and type 2 diabetes mellitus has been described since the last decade $[1,2]$. The prevalence and incidence of type 2 diabetes are higher in individuals infected by the hepatitis $\mathrm{C}$ virus (HCV), with or without cirrhosis, when compared to patients with chronic hepatitis B or to patients with other chronic hepatic diseases [3]. These findings suggest that HCV would be a factor leading to glucose intolerance and diabetes. Although there are evidences that diabetes is more common among patients infected with $\mathrm{HCV}$, cross-sectional studies have shown conflicting results when the frequency of HCV infection is analyzed in type 2 diabetes patients. Some studies have found that $\mathrm{HCV}$ was more common in diabetics than in general population [4-6], while others have not confirmed this finding [7-10].

In spite of the higher frequency of type 2 diabetes and glucose intolerance among HCV carriers, it would be equally important to know whether $\mathrm{HCV}$ is a significant risk factor for type 2 diabetes, influencing the prevalence of this metabolic syndrome and justifying screening of that infection in adult diabetic patients.

Brazil is a tropical country showing epidemiologic aspects of developing nations, such as areas with high endemicity of malaria, leishmaniasis, and leprosy, at the same time as characteristics of industrialized countries, such as rising rates

Received on 6 September 2007; revised 15 January 2008.

Address for correspondence: Dr. Francisco José Dutra Souto. Universidade Federal de Mato Grosso. Faculdade de Ciências Médicas. CCBS1, $2^{\text {nd }}$ piso. Avenida Fernando Corrêa da Costa, S/N - Bairro Coxipó. Cuiabá-MT. Zip code: 78.060-900. Phone: +55 6536158852 (University); Fax: +55 65 36158863. E-mail address: fsouto@terra.com.br. of cardiovascular diseases, obesity, and type 2 diabetes [11]. The relationship between HCV and diabetes, in the general population, has not been studied in Brazil, with the exception of a small transverse study in the Northern region of the country, which did not find $\mathrm{HCV}$-infected patients among the 80 diabetics analyzed [12].

\section{Material and Methods}

In an attempt to find out if infection by HCV is more frequent among diabetic patients in our region, a case-control study was conducted in order to compare type 2 diabetes patients under treatment with patients without diabetes or glucose intolerance undergoing other kinds of treatments. All participants were enrolled at outpatient units of the hospital of the Federal University of Mato Grosso, Cuiabá city, central Brazil. This hospital has the largest outpatient service providing medical care to diabetic population in the region. Individuals included as controls were matched by gender and age (+/- two years) at a ratio of 1:1 with the cases. We assumed that the prevalence of $\mathrm{HCV}$ infection in non-diabetics and diabetics would be $2.5 \%$ and $11.5 \%$, as found out by Simó et al. in Spain [5]. We calculated that with a two-sided alpha of 0.05 and a power of 0.80 , we needed a sample size of 183 on each group. The control group participants were selected from the Internal Medicine, Cardiology, or Gynecology outpatient units. Before being included, the control candidates were submitted to two glucose level tests performed at different times, the results of which had to be below $100 \mathrm{mg} / \mathrm{dL}$. Otherwise, they were discarded. Both groups were submitted to interviews, weight and height measurements, assessment of body mass index (BMI), and had blood sample taken for testing the presence of anti-HCV by $3^{\text {rd }}$ generation ELISA. These tests were performed in Central Laboratory of state of Mato Grosso, Cuiabá. The participants whose samples tested 
reactive were submitted to new collection of blood for $\mathrm{HCV}$ RNA testing by polymerase chain reaction (PCR). This test was performed using Amplicor HCV monitor (Roche Molecular Systems Inc., US) kits in Hermes Pardini Laboratory, Belo Horizonte, Brazil. An immunoblot assay (Chiron RIBA HCV strip immunoblot assay; Chiron Corporation, US) was performed in anti-HCV positive and PCR negative samples to confirm anti-HCV specificity in Central Laboratory, Cuiabá. The ethical aspects of the protocol were analyzed by the institution's Committee of Ethics for Research on Human Beings under number 190/2004, and approved on 12/15/2004.

\section{Results}

Between April and October of 2005, 217 type 2 diabetics were interviewed; however, there were nine losses due to absence for blood collection. Two other patients were discarded because they already knew that they were carriers of the HCV. To participate as control, 248 non-diabetic patients were approached. Two refused to participate. Forty candidates were discarded because they showed glucose levels above $99 \mathrm{mg} / \mathrm{dL}$. At the end, each group was composed of 206 individuals, with $72 \%$ females and an average age of 55 for the cases and 54.6 for the controls. The groups were similar in most variables, but there were more Afro-descendant among the cases $(20 \%$ versus $14 \% ; \mathrm{p}=0.15)$ and more Caucasians among the controls $(29 \%$ vs. $19 \% ; \mathrm{p}=0.03)$. Most of the participants were mulatto, which were equally distributed among the groups. The group of diabetics had a lower level of education, with a higher percentage of participants having not studied beyond the elementary school years $(79 \% v s$. $66 \% ; \mathrm{p}<0.01)$. It also showed lower income, with a larger percentage of individuals earning less than US $\$ 500$ per month (81\% vs. $67 \%$; $\mathrm{p}<0.01)$.
The groups did not show differences in height. However, the average weight among the diabetics $(72.8 \pm 15.2 \mathrm{Kg})$ was higher than that of the non-diabetic group $(65.1 \pm 12.6 \mathrm{Kg}$; $\mathrm{p}<$ $0.00001)$. This was reflected in a higher BMI average among the first group ( 29.3 versus $26.3 ; \mathrm{p}<0.00001)$. Forty-five $(21.8 \%)$ out of the 206 diabetics took insulin and $112(54.4 \%)$ took oral hypoglycemic drugs.

There was no difference in the prevalence of anti-HCV between the groups: three diabetics (1.4\%) were confirmed positive for anti-HCV by PCR or immunoblot, while among the controls, only two $(1 \%)$ were confirmed positive. In a multivariate analysis performed in order to identify variables independently associated to the diabetics group, just a BMI above $25 \mathrm{Kg} / \mathrm{m}^{2}$ and monthly earns below US\$ 500 were statistically significant (Table).

\section{Discussion}

As far as we know, this is the first Brazilian controlled study assessing association between $\mathrm{HCV}$ infection and type 2 diabetes mellitus in Brazil. There was only one study, conducted in the state of Amazonas, which did not find antiHCV reactivity in 80 diabetic patients, without using a comparison group [12]. Another study has just analyzed posthepatic transplant patients [13].

As expected, excess weight and obesity were more frequent among diabetics. We also found that the diabetics belonged to lower social and economic classes. Obesity, which is closely related to type 2 diabetes, has increased in lower-income patients and decreased in the higher-income patients, both in developed and developing nations [11,14]. Therefore, the social and demographic characteristics that differed in both groups seemed to be caused by global and national trends among patients with diabetes mellitus more than selection bias of control group.

Table. Multivariate analysis of variables associated with type 2 diabetes mellitus

\begin{tabular}{lcc}
\hline Variable & OR $(\mathbf{C I}$ 95\%) & $\mathbf{p}$ \\
\hline Body mass index $\left(\mathrm{Kg} / \mathrm{m}^{2}\right):$ & & - \\
$\quad \leq 25$ & 1.0 & 0.000 \\
$\quad 25-<30$ & $3.2(1.9-5.2)$ & 0.000 \\
$\quad \geq 30$ & $4.2(2.4-7.2)$ & - \\
Level of education & 1.0 & 0.18 \\
$\quad$ Elementary school or lower & $0.7(0.4-1.2)$ & - \\
$\quad$ High school or higher & 1.0 & 0.03 \\
Family income (monthly) & $1.8(1.1-3.2)$ & - \\
$\quad>$ US\$ 500 & 1.0 & 0.07 \\
$\quad \leq$ US\$ 500 & $0.6(0.4-1.0)$ & 0.34 \\
Race & $1.3(0.7-2.4)$ & - \\
$\quad$ Mulatto & 1.0 & 0.35 \\
$\quad$ White & & \\
Black & $2.6(0.3-18.9)$ & \\
Anti-HCV & & \\
$\quad$ Negative & & \\
$\quad$ Positive & & \\
\hline
\end{tabular}


Since a positive result for anti-HCV could be overestimated in diabetics, because they are patients treated in hospitals, the control group was composed of patients treated in outpatient units at the same institution. Therefore, cases and controls would have similar chances of exposure to $\mathrm{HCV}$ due to hospital procedures.

The present study was not able to reveal a difference in the frequency of infection by $\mathrm{HCV}$ between diabetics and non-diabetics, which is in agreement with the studies by Mangia et al. [7], Sotiropoulos et al. [8], Virseda et al. [9] and Wolff et al. [10]. On the other hand, this feature is in disagreement with the studies that found a higher prevalence of HCV infection in type 2 diabetic patients [2, 4-6]. Our study was designed to identify a 4.5 -fold difference of $\mathrm{HCV}$ infection prevalence between diabetics and non-diabetics. Since the HCV-positive patients were scarce among both groups, a lack of study power due to the sample size can be the reason for the non-difference between the groups. Thus, these data should be interpreted with caution. In any case, if $\mathrm{HCV}$ infection is in fact more common among diabetics than nondiabetics, the difference does not seem to be large. Our findings suggest that type 2 diabetes attributable to HCV should be infrequent, at least in our region.

Measures to exclude individuals already diagnosed with $\mathrm{HCV}$ were taken in order to avoid selection bias. Two patients, who already knew that they were carriers of the HCV, were excluded from the study. However, even if these two patients had been included in the cases group, there would not be a significant statistic association between HCV and diabetes.

The data presented herein does not allow us to recommend screening for $\mathrm{HCV}$ infection in diabetics, because we did not identify in this group a prevalence of anti-HCV above that expected for non-diabetics in the same age group. In order to justify screening for $\mathrm{HCV}$ in diabetics patients other indicative features for this infection should be considered, such as altered levels of aminotransferases or other signs of liver disease $[8,15]$.

\section{Acknowledgements}

The reagent kits used in this study were purchased with funds from the National Council for Scientific and Technological Development (CNPq - Conselho Nacional de Desenvolvimento Científico e Tecnológico) and the
Foundation for Research Support of the state of Mato Grosso (FAPEMAT - Fundação de Apoio à Pesquisa do Estado de Mato Grosso).

\section{References}

1. Grimbert S., Valensi P., Levy-Marchal C., et al. High prevalence of diabetes mellitus in patients with chronic hepatites C: a casecontrol study. Gastroenterol Clin Biol 1996;20:544-8.

2. Mehta S.H., Brancati F.L., Sulkowski M.S., et al. Prevalence of type 2 diabetes mellitus among persons with hepatitis $\mathrm{C}$ virus infection in the United States. Ann Intern Med 2000;133:5929.

3. Knobler H., Schihmanter R., Zifroni A., et al. Increased Risk of Type 2 Diabetes in Noncirrhotic Patients With Chronic Hepatitis C Virus Infection. Mayo Clinic Proc 2000;75:355-9.

4. Özyilkan E., Erbas E., Simsek H., et al. Increased prevalence of hepatitis $\mathrm{C}$ vírus antibodies in patients with diabetes mellitus. $\mathrm{J}$ Intern Med 1994;235:283-5.

5. Simó R., Hernandez C., Genesca J. et al. High prevalence of hepatitis $\mathrm{C}$ vírus infection in diabetic patients. Diabetes Care 1996;19:9981002 .

6. Mason A.L., Lau J.Y.N., Hoang N., et al. Association of diabetes mellitus and chronic hepatitis $\mathrm{C}$ virus infection. Hepatology 1999;29:328-333.

7. Mangia A., Schiavone G., Lezzi G., et al. HCV and Diabetes Mellitus: evidence for a negative association. Am J Gastroenterol 1998;93:2363-7.

8. Sotiropoulos A., Peppas T.A., Skliros E., et al. Low prevalence of hepatitis $\mathrm{C}$ virus infection in Greek diabetic patients. Diabet Med 1999; $16: 250-2$.

9. Virseda I., Jaqueti J., Nicolas M.D., et al. Virus de la hepatitis C y diabetes mellitus tipo 2, existe relación? Enferm Infecc Microbiol Clin 2002;20:92-7.

10. Wolff C., Munoz S., Raddatz V.. Existe asociación entre el vírus C de la hepatitis y la diabetes? Medicina 1999;59:315-6.

11. Monteiro C.A, D’A Benício M.H., Conde W.L., Popkin B.M. Shifting obesity trends in Brazil. Eur J Clin Nutr 2000;54:3426.

12. Coimbra C.L., Cabral J.M., Braga W.S.M., et al. Associação da infecção pelo vírus da hepatite $\mathrm{C}$ (VHC) e diabetes melitus tipo II. Rev Soc Bras Med Trop 2002;35 (suppl 1):275.

13. Parolin M.B., Zaina F.E., Araújo M.V., et al. Prevalence of newonset diabetes mellitus in Brazilian liver transplant recipients: association with HCV infection. Transplant Proc 2004;36:27767 .

14. Harris M.I., Flegal K.M., Cowie C.C., et al. Prevalence of diabetes, impaired fasting glucose, and impaired glucose tolerance in U.S. adults. The third national health and nutrition examination survey, 1988-1994. Diabetes Care 1998;21:518-24.

15. Gray H., Wreghitt T., Stratton I.M., et al. High prevalence of hepatitis $\mathrm{C}$ infection in Afro-Caribbean patients with type 2 diabetes and abnormal liver function tests. Diabet Med 1995; $12: 244-9$ 